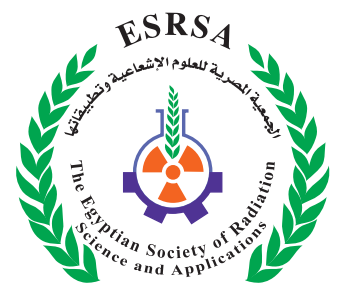

J. Nucl. Tech. Appl. Sci., Vol. 7, PP. 33 : 50 (2019)

\title{
Antioxidant and Antibacterial Activity of Gamma Irradiated Red Beet (Beta Vulgaris L.) Leaves and Roots
}

Elshiemy, S. M. ${ }^{1}$; Soliman, I. A ${ }^{1}$; Abdelaleem, M. A. ${ }^{1}$ and Elbassiony K.R.A. ${ }^{1,2}$

Received: 10/12/2018

Accepted: 23/12/2018

E.mail:Dr.sabry_elshiemy@yahoo.com

\section{KEYWORDS}

Red beet; Leaves, Roots; Antioxidant; Antibacterial; Irradiation.

\section{ABSTRACT}

The ethanol, methyl alcohol and acetone (80\%) extracts of gammairradiated red beet leaves and roots (at dose levels of 0, 3, 6, 9 and 12 kGy) were made to be used as a natural antioxidant and antibacterial agents. The total phenolic contents (TPC) and total flavonoid contents (TFC) were estimated in the leave and root extracts. The antioxidant activity was determined by DPPH and FRAP methods. Antibacterial activity was carried out against $S$. aureus, B. cereus, E. coli and S. typhimurium. The obtained results indicated that the ethanol extracts had higher total phenolics, flavonoids content and antioxidant activity in both leaves and roots than other solvents extract after solid-phase extraction. The results showed that $9 \mathrm{kGy}$ doses significantly increased the TPC, TFC and enhanced the antioxidant activity of leaves and roots. The majority trend in obtaining data summarized that both non-irradiated and irradiated red beet roots (RBR) extracts possess higher antibacterial activity against selected bacteria than red beet leaves (RBL) extracts. Last, the obtained data showed that red beet is a very bright source of bioactive compounds and it is a very potent natural source of antioxidant compounds.

1. Plant Research Department, Radioisotopes Application Division, Nuclear Research Center, Atomic Energy Authority, Egypt,13759.

2. Food Science and Technology College, Huazhong Agricultural Universit, Wuhan, 430070, P. R. China. 


\section{INTRODUCTION}

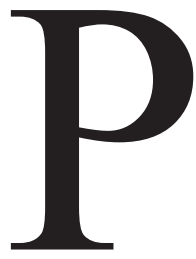

henolic compounds include many organic substances that all possess an aromatic ring with one or more substituted hydroxyl groups and a functional side-chain. It is well known that the majority of the plant extracts contain phenolic compounds as secondary metabolites. Antioxidant compounds such as flavonoids, tannins, coumarins, curcuminoids, xanthones, lignans and terpenoids are found in different parts of the plant, e.g., fruits, vegetables, leaves and seeds (Vaithiyanathan $\boldsymbol{e t}$ al., 2011). Therefore, there is a growing interest in separating these bioactive compounds and using them as natural antioxidants.

The association between the diet rich in fruits and vegetables and a decreased risk of cardiovascular diseases and certain forms of cancer is supported by considerable epidemiological evidence (Riboli and Norat, 2003). Different studies showed that free radicals present in the human organism cause oxidative damage to various molecules, such as lipids, proteins, and nucleic acids, and are thus involved in the initiation phase of the degenerative diseases. Phenolic and other phytochemical antioxidants found in fruits and vegetables are capable of neutralizing free radicals and may play a major role in the prevention of certain diseases (Kaur and Kapoor, 2001).

Beet root ranks among the 10 most powerful vegetables with respect to its antioxidant capacity ascribed to a total phenolic content of $50-60 \mu \mathrm{mol} / \mathrm{g}$ dry weight (Kähkönen et al., 1999). Beet root is a potential source of valuable water-soluble nitrogen pigments, called betalains, which comprise two main groups, the red betacyanins and the yellow betaxanthins. They are free radical scavengers and prevent active oxygen-induced and free radical-mediated oxidation of biological molecules (Pedreno and Escribano, 2001).
A more recent investigation showed that total phenolic content decreases in the order peel $(50 \%)$, crown (37\%), and flesh (13\%). The peel also carries the main portion of betalains with up to $54 \%$, their content being lower in the crown (32\%) and flesh (14\%) (Kujala et al., 2000).

Nowadays, there is an increasing interest in the substitution of synthetic food antioxidants by natural ones. The antioxidant compounds from waste products of food industry could be used for protecting the oxidative damage in living systems by scavenging oxygen free radicals, and also for increasing the stability of foods by preventing lipid peroxidation (Makris et al., 2007). Special attention was focused on their extraction from inexpensive sources. In recent years, many vegetal extracts rich in phenolic compounds have been put on the market as functional ingredients (Fernández-Ginés et al., 2005). Nevertheless, the use of vegetal extracts as functional ingredients in meat products should be supported by the evaluation of the phenolic content in these products and their evolution during shelf life (Fernández-López et al., 2007).

The treatment of food by ionizing radiation has been approved by several authorities (Food and Drug Administration (FDA), United States Department of Agriculture (USDA), WHO, FAO) and scientific societies based on extensive research (Morehouse, 2002). The irradiation of foodstuffs is an effective, environmentally friendly solution which is authorized in more than 50 different countries all over the world and for various kinds of food products. Consumers, knowing the benefits of this technology tend to choose irradiated foods with confidence (Loaharanu and Thomas, 2001).

On the other hand, Irradiation can influences the level of antioxidants/ phytochemicals and the capacity of a specific plant to produce them at different levels. Under certain favourable conditions, 
the concentration of plant phytochemicals might be enhanced. These conditions include exposure to radiation sources, wounding, storage at low temperatures, and/or exposure to extreme temperatures (Zobel, 1997). Gamma irradiation at a dose level of $10 \mathrm{kGy}$ increased phenolic acid content in cinnamon and clove, while the phenolic content in nutmeg remained unaltered (Variyar et al., 1998). Although, some studies reported that, gamma irradiation does maintain or enhance the antioxidant properties, there are a few examples wherein the antioxidant properties of the plant material were decreased (Alothman et al., 2009). To the best of our knowledge, there are no published studies on the effect of ionizing radiation on the phytochemicals content, antioxidant and antimicrobial activities of red beet.

The goal of this work was to examine the ethanol, methanol and acetone (80\%) extracts of $\gamma$-irradiated red beet (Beta Vulgaris L.) leaves and roots (at dose levels of $0,3,6,9$ and $12 \mathrm{kGy}$ ) as a natural antioxidant and antibacterial agents.

\section{MATERIALS AND METHODS}

\section{Material}

Red beet (Beta Vulgaris L.) samples:

Mature red beet (Beta Vulgaris L.) fruits had no visible external cuts or spoilage were purchased from the local market, Zagazig, Sharkia governorate, Egypt. The roots were separated from leaves manually, rinsed with distilled water to remove soil particles then the samples were oven dried at $45^{\circ} \mathrm{C}$ for $72 \mathrm{hr}$. The dried plant material was ground into a fine powder in an electric grinder. The grounded red beet samples were macerated in hexane to remove lipids, then dried at $70{ }^{\circ} \mathrm{C}$ to remove hexane residue. The samples were packaged in polyethylene pouches (50 $\pm 2 \mathrm{~g}$ ) for gamma irradiation treatment.

\section{Chemicals and Reagents:}

Butylated Hydroxy Toluene (BHT), 1, 1-Diphenyl-2-Picrylhydrazyl (DPPH), Gallic acid, Quercetin and Folin- Ciocalteu reagent was purchased from Sigma (St. Louis, MO, USA). All other used chemicals were analytical grade.

\section{Bacterial Strains:}

Bacterial strains used for the determination of antibacterial activity were Gram-negative bacteria: Escherichia coli (ATCC 25922) and Salmonella typhimurium (ATCC 98031), besides Gram-positive bacteria: Bacillus cereus (ATCC 7064) and Staphylococcus aureus (ATCC 25923). The selected strains were obtained from the Egyptian Microbial Culture Collection, Faculty of Agriculture, Ain Shams University.

\section{Bacterial Media:}

Mueller Hinton agar and Mueller Hinton broth medium were used according to Bridson (2006) and purchased from Difco Co., Detroit, MI, USA.

\section{Methods}

\section{Irradiation Treatments:}

Red beet powder samples were subjected to gamma irradiation at dose levels of 0, 3, 6, 9 and 12 kGy using a ${ }^{60} \mathrm{Co}$ Russian gamma chamber, (dose rate $1.3 \mathrm{kGy} / \mathrm{hr}$ ), belonging to Cyclotron Project, Nuclear Research Center, Atomic Energy Authority, Cairo, Egypt.

\section{Preparation of Red beet Extracts:}

The non-irradiated and gamma irradiated red beet powder samples were extracted by direct soaking with ethanol, methanol and acetone (80\%). Briefly, $20 \mathrm{~g}$ of plant material was soaked with 200 $\mathrm{mL}$ of solvent in dark bottles at room temperature overnight by shaking the mixture at a speed of 1000 
vibration $/ \mathrm{min}$. The extracts were filtered through Whatman filter paper No. 42 and the residue was extracted again with $100 \mathrm{ml}$ of respective solvent to ensure the complete extraction of phenolic compounds. The filtrate was subjected to the rotary evaporator at $40^{\circ} \mathrm{C}$ under reduced pressure to remove the solvent. The extracts were stored in brown bottles at $-18^{\circ} \mathrm{C}$ to further analyses.

\section{Determination of Total Phenolics Content (TPC):}

Total phenolic content was determined by the Folin-Ciocalteu method according to ArabshahiDelouee and Urooj (2007). A $200 \mu \mathrm{L}$ of extract solution was mixed with $1 \mathrm{~mL}$ of Folin-Ciocalteu's reagent ( $1 \mathrm{ml}$ reagent with $9 \mathrm{ml}$ distilled water) after $5 \mathrm{~min}$ added $1.5 \mathrm{~mL}$ distilled water and $1 \mathrm{~mL}$ of $75 \mathrm{~g}$ $\mathrm{L}^{-1} \mathrm{Na}_{2} \mathrm{CO}_{3}$ solution. The mixture was incubated in a shaking incubator at ambient temperature for $60 \mathrm{~min}$ and its absorbance at $760 \mathrm{~nm}$ was measured. Gallic acid was used as a standard for the calibration curve. Total phenolic content expressed as Gallic acid equivalent (GAE) was calculated using the following linear equation based on the calibration curve:

$\mathrm{Y}=0.0045 \mathrm{X}+0.0743\left(\mathrm{R}^{2}=0.9944\right)$

Where:

$\mathrm{Y}$ is the absorbance and $\mathrm{X}$ is the concentration ( $\mathrm{mg}$ $\mathrm{GAE} \mathrm{g}^{-1}$ extract) $\mathrm{R}^{2}=$ Correlation Coefficient.

\section{Determination of Total Flavonoids Content (TFC):}

Total flavonoids content was determined by the method of Ordon et al. (2006). An aliquot $(0.5 \mathrm{~mL})$ of $20 \mathrm{gL}^{-1} \mathrm{AlCl}_{3}$ Ethanol solution was added to 0.5 $\mathrm{mL}$ of extracting solution. The absorbance was measured after $1 \mathrm{hr}$ at room temperature at $420 \mathrm{~nm}$. A yellow colour indicated the presence of flavonoids. Extracted samples were evaluated at a final concentration of $0.1 \mathrm{mg} \mathrm{mL}^{-1}$. Total flavonoid content was expressed as quercetin equivalent (QE) and calculated using the following equation based on the calibration curve:
$\mathrm{Y}=0.0072 \mathrm{X}\left(\mathrm{R}^{2}=0.9853\right)$

Where:

$\mathrm{Y}$ is the concentration ( $\mathrm{mg} \mathrm{QE} \mathrm{g}^{-1}$ extract), $\mathrm{X}$ is the absorbance and $\mathrm{R}^{2}=$ Correlation Coefficient.

Antioxidant Activity of Extracts

\section{DPPH Radical-scavenging Activity:}

The electron donation ability of the obtained extracts was measured by bleaching of the purple coloured solution of DPPH according to the method of Hanato et al. (1988). One hundred $\mu \mathrm{L}$ of each extract was added to $3 \mathrm{~mL}$ of $0.1 \mathrm{mM}$ DPPH dissolved in toluene, ethanol and methanol according to the solvent used for extraction. After an incubation period of $0,30,60$ and $120 \mathrm{~min}$ at room temperature, the absorbance was determined against control at $517 \mathrm{~nm}$ (Gulcin et al., 2004). Percentage of antioxidant activity of free radical DPPH was calculated as follows:

Antioxidant activity (Inhibition) $\%=\left[\left(\mathrm{A}_{\text {control }}-\mathrm{A}_{\text {sample }}\right)\right.$ $\left./ \mathrm{A}_{\text {control }}\right]$ x 100

Where:

$\mathrm{A}_{\text {control }}$ is the absorbance of the control reaction and $\mathrm{A}_{\text {sample }}$ is the absorbance in the presence of plant extract. BHT was used as a positive control. Samples were analysed in triplicate.

\section{Ferric Reducing Antioxidant Power (FRAP):}

The Reducing power of all extracts was measured by the method of Oyaizu (1986) and modified by Gülçin et al. (2010). The reduction of $\mathrm{Fe}^{+3}$ to $\mathrm{Fe}^{+2}$ was determined by measuring the absorbance of Perl's Prussian blue complex. This method is based on the reduction of $\left(\mathrm{Fe}^{+3}\right)$ ferricyanide in stoichiometric excess relative to the antioxidants. For this purpose, $0.1 \mathrm{~mL}$ of each extract mixed with $1 \mathrm{ml}$ of $0.2 \mathrm{M}$ sodium phosphate buffer $(\mathrm{pH} 6.6)$ and $1 \mathrm{ml}$ $(1 \%)$ of potassium ferricyanide $\left[\mathrm{K}_{3} \mathrm{Fe}\left(\mathrm{CN}_{6}\right)\right]$. The 
mixture was incubated at $50^{\circ} \mathrm{C}$. After $20 \mathrm{~min}$ of incubation, the reaction mixture was acidified with 1 $\mathrm{ml}$ of trichloroacetic acid (10\%). Finally, $0.25 \mathrm{ml}$ of $\mathrm{FeCl}_{3}(0.1 \%)$ was added to this solution. Distilled water was used as blank and for control. The absorbance of the mixture was measured at $700 \mathrm{~nm}$ using a UV spectrophotometer. Decreased absorbance indicates the ferric reducing power capability of the sample.

\section{Determination of Antibacterial Activity}

\section{Agar-Well Diffusion Assay:}

To determine the inhibitory activity of both extracts from beet roots and beet leaves, plates were made by adding approximately $10^{6} \mathrm{CFU} / \mathrm{ml}$ (Andrews, 2001) to Petri dishes containing Muller Hinton agar. Around $7 \mathrm{~mm}$ diameter wells were made with pre-inoculated media and each well was inoculated with $100 \mu \mathrm{l}$ of each extract. After diffusion at 4 $\pm 1^{\circ} \mathrm{C}$ for $1 \mathrm{~h}$., the plates were incubated at $37^{\circ} \mathrm{C}$ for $24 \mathrm{~h}$. The diameters of the inhibition zones around the wells were measured with a caliper (Bennett $\boldsymbol{e t}$ al., 1966).

\section{Statistical analysis:}

All the experiments were carried out in triplicate and mean and standard error was calculated. Then the results were subjected to two-way analysis of variance followed by Duncan's significant differences using the generalized linear model procedure of the SAS program (version 9.1.3) software (Cary, NC). Significance levels were defined as $p<0.05$ (SAS, 2004).

\section{RESULTS:}

\section{Effect of gamma irradiation on TPC of red beet roots (RBR) and red beet leaves (RBL) extracts:}

The extracts of RBR and RBL samples, show a significant difference between extracts (ethanol 80\% $>$ methanol $80 \%>$ acetone $80 \%$ ) obtained in TPC as shown in Table 1. Moreover, the TPC of RBR extracts were significantly higher than those of the RBL in obtaining extracts due to its containing larger amounts of phenolic compounds and pigments than RBL. In addition, the extracting ability of ethanol was significantly higher than other examined solvents which were $772.422 \pm 5.466 \mathrm{mg}$ GAE $100 \mathrm{~g}^{-1}$ DW for RBR and $457.98 \pm 3.214 \mathrm{mg}$ GAE $100 \mathrm{~g}^{-1} \mathrm{DW}$ for samples of non-irradiated RBL extracts compared to methanol was $710.655 \pm 2.266$ and $429.063 \pm 5.594 \mathrm{mg}$ GAE $100 \mathrm{~g}^{-1}$ DW and acetone was $612.790 \pm 3.195$ and $409.656 \pm$ 4.837mg GAE $100 \mathrm{~g}^{-1} \mathrm{DW}$ for RBR and RBL, respectively.

Meanwhile, the data presented in Table 1 clearly showed that the low-polarity solvents, particularly acetone $80 \%$ have a significant low ability for extracting TPC in both RBR and RBL extracts were $612.790 \pm 3$. 195 and 409. $626 \pm 4.837$ mg GAE $100 \mathrm{~g}^{-1}$ DW compared to methanol $80 \%$ extracts were $710.655 \pm 2.266$ and $429.063 \pm 5.594 \mathrm{mg} \mathrm{GAE} 100 \mathrm{~g}^{-1} \mathrm{DW}$, respectively.

For irradiated RBR and RBL samples, at dose levels of 3, 6, 9 and $12 \mathrm{kGy}$ irradiation treatment enhanced the TPC of all obtained extracts compared to corresponding non-irradiated samples. Otherwise, the extracts obtained from treated samples at a dose level of $9 \mathrm{kGy}$ have a clear significant $(\mathrm{p}<0.05)$ increase in TPC as compared to that of the corresponding control samples and other doses. In the case of methanol $80 \%$ and acetone $80 \%$, the irradiation increased the TPC and has the same manner of acting for TPC in RBR and RBL samples.

Therefore, TPC contents of ethanol extract samples were found to be $824.87 \pm 3.148$ and $476.503 \pm 4.600$, $772.422 \pm 5.466$ and $457.98 \pm 3.214,786.166 \pm 5.519$ and $804.57 \pm 1994$ and $775.266 \pm 2.260,461.906 \pm$ $2.922 \& 464.892 \pm 1.636$ and $460.192 \pm 1.395 \mathrm{mg} \mathrm{GAE}$ 100 g-1 (DW) of RBR and RBL for irradiated at a dose level of $9 \mathrm{kGy}$, control and irradiated at dose levels of 3, 6 and $12 \mathrm{kGy}$ samples, respectively. 
Table (1) : Total phenolic content (TPC) (mg GAE $\left.100 \mathrm{~g}^{-1} \mathrm{DW}\right)$ of non-irradiated and irradiated red beet roots and leaves extracts.

\begin{tabular}{|c|c|c|c|c|c|c|}
\hline \multirow{3}{*}{$\begin{array}{l}\gamma \text {-irradiation } \\
\text { doses }(k G y)\end{array}$} & \multicolumn{6}{|c|}{ Extraction Solvents } \\
\hline & \multicolumn{3}{|c|}{ RBR } & \multicolumn{3}{|c|}{ RBL } \\
\hline & Eth $80 \%$ & Meth 80\% & Acet $\mathbf{8 0 \%}$ & Eth $80 \%$ & Meth 80\% & Acet $80 \%$ \\
\hline $\mathbf{0}$ & $\begin{array}{c}772.422 \\
\pm 5.466^{\mathrm{Da}}\end{array}$ & $\begin{array}{r}710.655 \\
\pm 2.266^{\mathrm{Db}}\end{array}$ & $\begin{array}{c}612.790 \\
\pm 3.195^{\mathrm{Ec}}\end{array}$ & $\begin{array}{c}457.98 \\
\pm 3.214^{\mathrm{Ba}}\end{array}$ & $\begin{array}{c}429.063 \\
\pm 5.594^{\mathrm{Bb}}\end{array}$ & $\begin{array}{c}409.656 \\
\pm 4.837^{\mathrm{Cc}}\end{array}$ \\
\hline 3 & $\begin{array}{l}786.166 \\
\pm 5.619^{\mathrm{Ca}}\end{array}$ & $\begin{array}{r}736.483 \\
\pm 2.125^{\mathrm{Cb}} \\
\end{array}$ & $\begin{array}{c}676.848 \\
\pm 2.751^{\mathrm{Cc}}\end{array}$ & $\begin{array}{l}461.906 \\
\pm 2.922^{\mathrm{Ba}}\end{array}$ & $\begin{array}{c}443.771 \\
\pm 5.017^{\mathrm{ABb}}\end{array}$ & $\begin{array}{r}420.936 \\
\pm 3.015^{\mathrm{BCc}}\end{array}$ \\
\hline 6 & $\begin{array}{c}804.57 \\
\pm 1.994^{\mathrm{Ba}}\end{array}$ & $\begin{array}{r}746.515 \\
\pm 1.114^{\mathrm{Bb}}\end{array}$ & $\begin{array}{c}685.853 \\
\pm 3.358^{\mathrm{Bc}}\end{array}$ & $\begin{array}{c}464.892 \\
\pm 1.636^{\mathrm{Ba}} \\
\end{array}$ & $\begin{array}{c}448.802 \\
\pm 1.847^{\mathrm{Ab}}\end{array}$ & $\begin{array}{r}423.589 \\
\pm 3.428^{\mathrm{Bc}}\end{array}$ \\
\hline 9 & $\begin{array}{c}824.87 \\
\pm 3.148^{\mathrm{Aa}}\end{array}$ & $\begin{array}{c}761.127 \\
\pm 1.164^{\mathrm{Ab}} \\
\end{array}$ & $\begin{array}{c}708.127 \\
\pm 2.449^{\mathrm{Ac}} \\
\end{array}$ & $\begin{array}{l}476.503 \\
\pm 4.600^{\text {Aa }}\end{array}$ & $\begin{array}{c}455.824 \\
\pm 3.459^{\mathrm{Ab}}\end{array}$ & $\begin{array}{c}436.196 \\
\pm 4.186^{\mathrm{Ac}}\end{array}$ \\
\hline 12 & $\begin{array}{r}775.266 \\
\pm 2.260^{\mathrm{CDa}}\end{array}$ & $\begin{array}{c}730.085 \\
\pm 4.897^{\mathrm{Cb}}\end{array}$ & $\begin{array}{c}655.601 \\
\pm 1.542^{\mathrm{Dc}}\end{array}$ & $\begin{array}{c}460.192 \\
\pm 1.395^{\mathrm{Ba}}\end{array}$ & $\begin{array}{c}442.333 \\
\pm 5.291^{\mathrm{ABb}}\end{array}$ & $\begin{array}{c}419.664 \\
\pm 4.208^{\mathrm{BCc}}\end{array}$ \\
\hline
\end{tabular}

Means with the same capital letter in the same columns are not significant $(\mathrm{p}<0.05)$ different; means with the same small letter in the same rows are not significant $(\mathrm{p}<0.05)$ different.

\section{Effect of gamma irradiation on TFC of RBR and $R B L$ extracts:}

The flavonoids data need to be examined because the antioxidant activity does not always relate to the presence of large quantities of polyphenolic com- pounds. Data in Table 2 revealed that the TFC of RBR and RBL extracts were significantly varied and the RBR extracts were significantly possessed TFC higher than RBL extracts. Whereas, the TFC in nonirradiated RBR samples extracted by ethanol have a significant increment in TFC $(598.821 \pm 1.619 \mathrm{mg}$ QE $\left.100 \mathrm{~g}^{-1} \mathrm{DW}\right)$ compared to other extracts which were $524.524 \pm 1.501$ and $487.005 \pm 3.686 \mathrm{mg} \mathrm{QE}$ $100 \mathrm{~g}^{-1} \mathrm{DW}$ for methanol and acetone, respectively.

Table (2) : Total flavonoids content (TFC) (mg QE $\left.100 \mathrm{~g}^{-1} \mathrm{DW}\right)$ of non-irradiated and irradiated red beet roots and leaves extracts.

\begin{tabular}{|c|c|c|c|c|c|c|}
\hline \multirow{2}{*}{$\begin{array}{c}\gamma \text {-irradiation } \\
\text { doses (kGy) }\end{array}$} & \multicolumn{5}{|c|}{ Extraction Solvents } \\
\cline { 2 - 7 } & $\mathbf{E B R}$ & \multicolumn{3}{c|}{ RBL } \\
\cline { 2 - 7 } & $\mathbf{E t h} \mathbf{8 0}$ & Meth 80\% & Acet 80\% & Eth 80\% & Meth 80\% & Acet 80\% \\
\hline \multirow{2}{*}{$\mathbf{0}$} & 598.821 & 524.524 & 487.005 & 368.524 & 315.701 & 274.727 \\
& $\pm 1.619^{\mathrm{Da}}$ & $\pm 1.501^{\mathrm{Cb}}$ & $\pm 3.686^{\mathrm{Cc}}$ & $\pm 2.152^{\mathrm{Da}}$ & $\pm 4.063^{\mathrm{Cb}}$ & $\pm 1.710^{\mathrm{Cc}}$ \\
\hline \multirow{2}{*}{$\mathbf{3}$} & 606.473 & 535.384 & 496.631 & 385.556 & 323.600 & 282.872 \\
& $\pm 2.601^{\mathrm{Ca}}$ & $\pm 4.275^{\mathrm{BCb}}$ & $\pm 3.456^{\mathrm{Bc}}$ & $\pm 6.432^{\mathrm{Ca}}$ & $\pm 4.275^{\mathrm{BCb}}$ & $\pm 2.262^{\mathrm{BCc}}$ \\
\hline \multirow{2}{*}{$\mathbf{6}$} & 615.112 & 544.517 & 503.049 & 402.587 & 329.771 & 288.796 \\
& $\pm 0.653^{\mathrm{Ba}}$ & $\pm 5.430^{\mathrm{ABb}}$ & $\pm 2.355^{\mathrm{Bc}}$ & $\pm 2.431^{\mathrm{Ba}}$ & $\pm 2.749^{\mathrm{ABb}}$ & $\pm 2.137^{\mathrm{Bc}}$ \\
\hline \multirow{2}{*}{$\mathbf{9}$} & 634.235 & 560.561 & 511.688 & 422.798 & 341.372 & 303.360 \\
& $\pm 2.288^{\mathrm{Aa}}$ & $\pm 4.504^{\mathrm{Ab}}$ & $\pm 1.710^{\mathrm{Ac}}$ & $\pm 2.285^{\mathrm{Aa}}$ & $\pm 4.275^{\mathrm{Ab}}$ & $\pm 3.265^{\mathrm{Ac}}$ \\
\hline \multirow{2}{*}{$\mathbf{1 2}$} & 603.291 & 541.555 & 498.359 & 388.841 & 330.512 & 283.856 \\
& $\pm 2.918^{\mathrm{CDa}}$ & $\pm 8.490^{\mathrm{BCb}}$ & $\pm 1.864^{\mathrm{Bc}}$ & $\pm 3.460^{\mathrm{Ca}}$ & $\pm 3.429^{\mathrm{ABb}}$ & $\pm 3.209^{\mathrm{Bc}}$ \\
\hline
\end{tabular}

Means with the same capital letter in the same columns are not significant $(p<0.05)$ different; means with the same small letter in the same rows are not significant $(p<0.05)$ different. 
Meanwhile, the extracts of non- irradiated RBL samples have the same manner of acting for TFC, where the RBL sample extracted by ethanol has a higher TFC $\left(368.524 \pm 2.152 \mathrm{mg}\right.$ QE $\left.100 \mathrm{~g}^{-1} \mathrm{DW}\right)$ than that of the RBL sample extracted with methanol, and acetone which was $315.701 \pm 4.063$ and $274.727 \pm 1.710 \mathrm{mg}$ QE $100 \mathrm{~g}^{-1} \mathrm{DW}$, respectively. For irradiated RBR and RBL samples, at dose levels of (3, 6, 9 and $12 \mathrm{kGy}$ ) enhanced the TFC of obtaining extracts compared to corresponding control samples. Moreover, the gamma irradiation processed samples at a dose level of 9 kGy obviously affected the production of flavonoids and caused significantly $(\mathrm{p}<$ 0.05 ) higher content in the ethanol, methanol and acetone extracts were found to be $634.235 \pm 2.288$, $560.561 \pm 4.504$ and $511.688 \pm 1$. \& RBL samples $(422.798 \pm 2.285,341 \pm 4.275$ and $303.360 \pm 3.265 \mathrm{mg}$ QE $100 \mathrm{~g}^{-1} \mathrm{DW}$ ) for RBR and RBL samples, respectively compared to that of corresponding control and other doses.

\section{Antioxidant activity of $R B R$ and $R B L$ extracts:}

No single method is adequate for evaluating the antioxidant capacity of foods or extracts, since different methods can widely yield diverging results. Thus, several methods based on different mechanisms should be used.

\section{Antioxidant activity of beet leaves and root extracts}

\section{DPPH Radical-Scavenging Activity:}

The scavenging effect of RBR, RBL extracts and BHT on DPPH radical were compared and expressed as \% (Tables 3 and 4).

It is obvious that all extracts obtained from nonirradiated and irradiated RBR and RBL samples that contained amounts of TPC were exhibited antioxidant activity particularly all RBR showed significantly $(\mathrm{p}<0.05)$ high antioxidant activity when compared with that of RBL and BHT, whereas the DPPH radical scavenging activity after $120 \mathrm{~min}$ of the control sample of RBR extracted by ethanol
$(88.35 \pm 0.001 \%)$ was significantly $(\mathrm{p}<0.05)$ higher than that extracted by methanol and acetone (77.14 \pm 0.005 and $60.90 \pm 0.003 \%$, respectively) compared to BHT sample which was $69.77 \pm 0.006 \%$. The same manner of acting for DPPH radical scavenging activity after $120 \mathrm{~min}$ was represented by RBL extracts which have a significant increasing ( $p$ $<0.05)(73.16 \pm 0.008 \%)$ in the samples extracted by ethanol compared to that RBL samples extracted by, methanol and acetone (66.52 \pm 0.007 and 48.58 $\pm 0.004 \%$, respectively) and BHT sample $(69.77 \pm$ $0.006 \%$ ) after $120 \mathrm{~min}$.

Exposing samples of RBR and RBL to gamma irradiation at dose levels of $(3,6,9$ and $12 \mathrm{kGy}$ enhanced the DPPH radical-scavenging ability of all extracts compared to corresponding non-irradiated samples. Particularly, data showed that all the assessed extracts of RBR samples treated with $9 \mathrm{kGy}$ had a significant ability to reduce the stable purplecolored radical DPPH into yellow-colored DPPH-H which it was $95.29 \pm 0.005 \%, 87.59 \pm 0.008 \%$ and $74.63 \pm 0.007 \%$, after $120 \mathrm{~min}$ for RBR samples extracted by ethanol, methanol and acetone, respectively compared to corresponding control, other doses and the synthetic antioxidant BHT which exhibited the lowest scavenging activity with the lowest value $69.77 \pm 0.006 \%$ after $120 \mathrm{~min}$.

The antioxidant activity of the ethanol and methanol extracts of irradiated RBL at dose level of 9 kGy against DPPH radicals significantly increased and reached up to $82.18 \pm 0.003$ and $71.03 \pm 0.011$ compared corresponding irradiated at dose levels of 3,6 and $12 \mathrm{kGy}(75.10 \pm 0.004,77.70 \pm 0.007$ and $75.18 \pm 0.006 \& 68.10 \pm 0.005,69.83 \pm 0.005$ and $67.16 \pm 0.006)$, non-irradiated RBL samples (73.16 \pm $0.008 \%$ and $66.52 \pm 0.007 \%$, respectively) and BHT sample $(69.77 \pm 0.006 \%)$ after $120 \mathrm{~min}$. Otherwise, significant decreasing in the antioxidant activity was observed in the acetone extract of the irradiated RBL at all applied doses compared to BHT sample (69.77 $\pm 0.006 \%$ ) after $120 \mathrm{~min}$. 
Table (3) : DPPH radical scavenging activity of non-irradiated and irradiated RBR extracts compared with BHT.

\begin{tabular}{|c|c|c|c|c|c|c|}
\hline 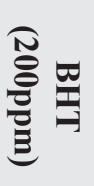 & $\bar{N}$ & 0 & $a$ & $\omega$ & $\theta$ & : \\
\hline 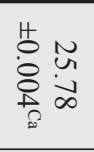 & 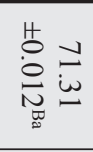 & 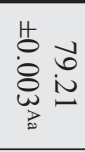 & 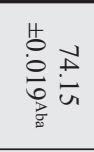 & 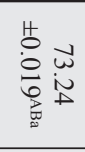 & 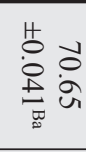 & $\stackrel{\ominus}{E}$ \\
\hline 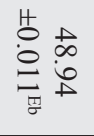 & 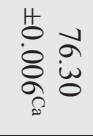 & 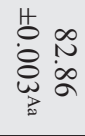 & 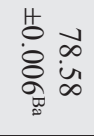 & $\begin{array}{l}+ \\
\dot{0} \\
0 \\
0\end{array}$ & 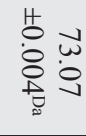 & $\begin{array}{l}\mathscr{E} \\
\stackrel{E}{E}\end{array}$ \\
\hline 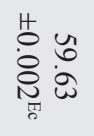 & 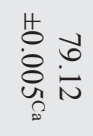 & $\begin{array}{l}\frac{1}{\dot{0}} \\
\dot{0} \\
0 \\
0 \\
0 \\
0\end{array}$ & 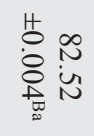 & 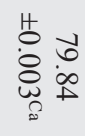 & 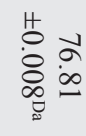 & $\begin{array}{l}\text { हे } \\
\text { E. }\end{array}$ \\
\hline 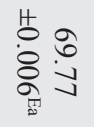 & 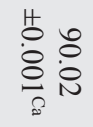 & 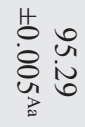 & 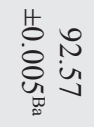 & 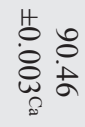 & 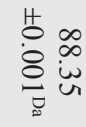 & $\underline{E}$ \\
\hline 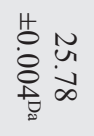 & 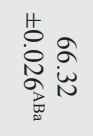 & 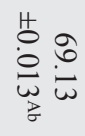 & 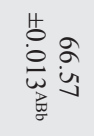 & 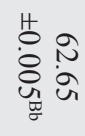 & 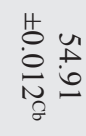 & $\stackrel{0}{0}$ \\
\hline 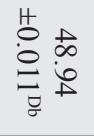 & 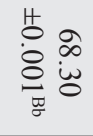 & 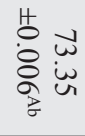 & 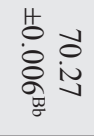 & 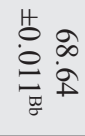 & 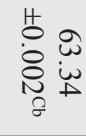 & $\begin{array}{l}\mathscr{E} \\
\stackrel{E}{E} \\
E\end{array}$ \\
\hline 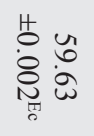 & 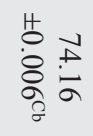 & 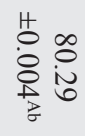 & 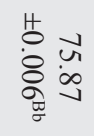 & 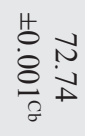 & 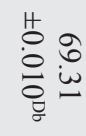 & $\begin{array}{l}\text { हे } \\
\text { E. }\end{array}$ \\
\hline 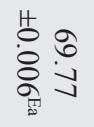 & 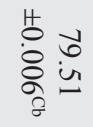 & 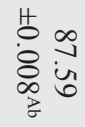 & 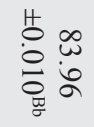 & 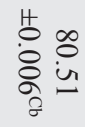 & 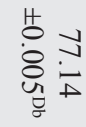 & $\underline{\underline{z}}$ \\
\hline 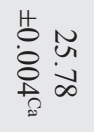 & 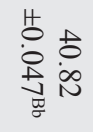 & 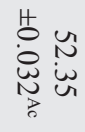 & 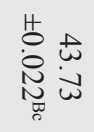 & 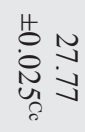 & 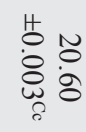 & $\stackrel{\bar{E}}{\text { E. }}$ \\
\hline 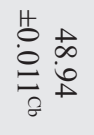 & 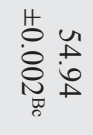 & 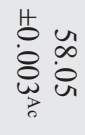 & 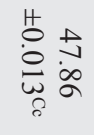 & 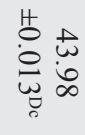 & 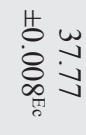 & 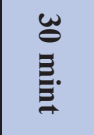 \\
\hline 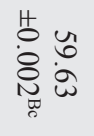 & 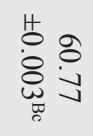 & 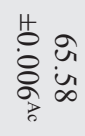 & 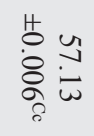 & 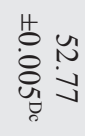 & 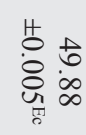 & $\begin{array}{l}\text { oे } \\
\text { E. }\end{array}$ \\
\hline 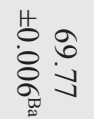 & $\begin{array}{l}4 \\
0 \\
0 \\
0\end{array}$ & 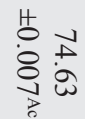 & 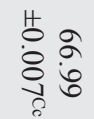 & 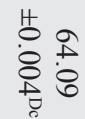 & 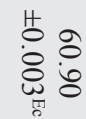 & E. 증 \\
\hline
\end{tabular}


Table (4) : DPPH radical scavenging activity of non-irradiated and irradiated RBL extracts compared with BHT.

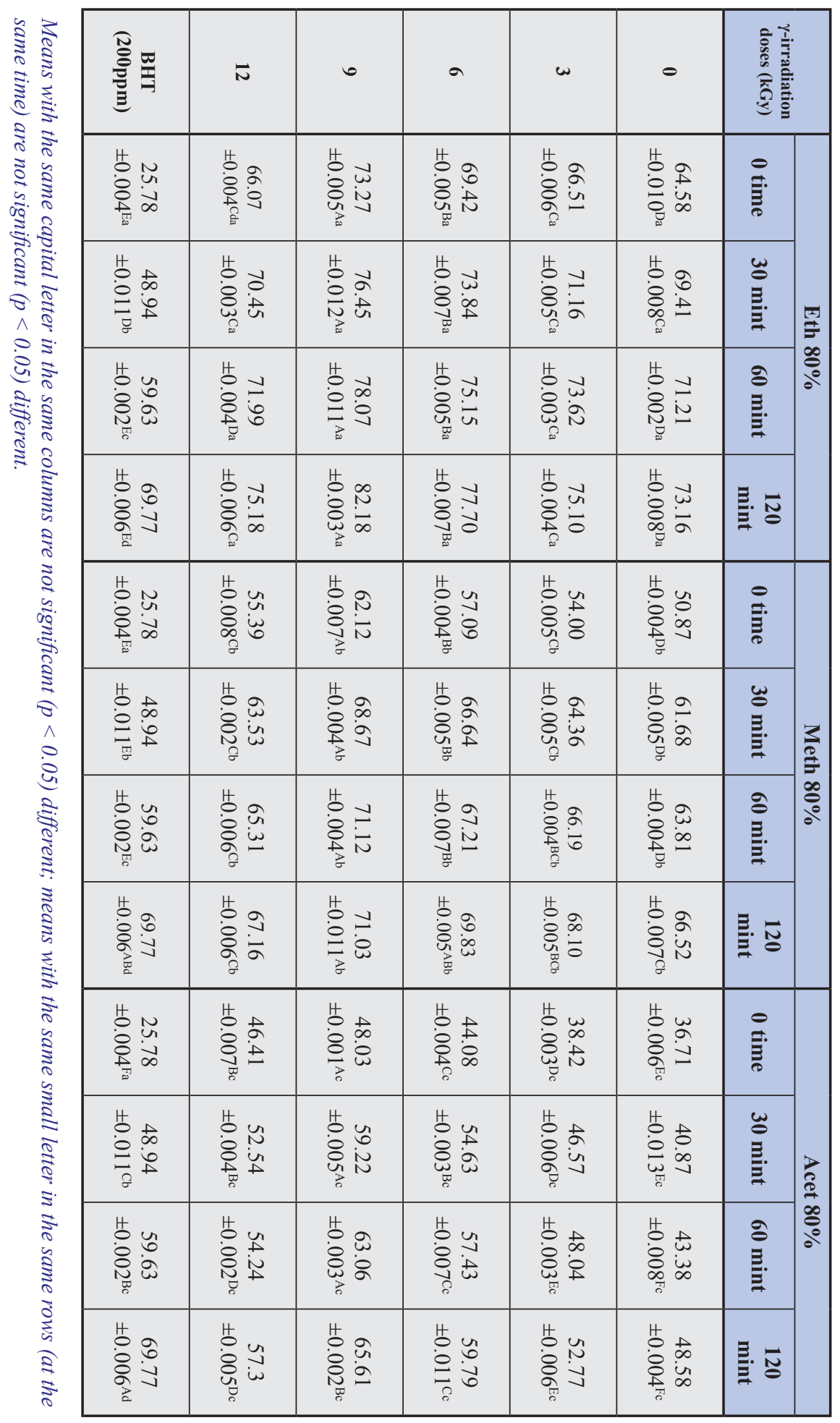


Ferric Reducing Antioxidant Power (FRAP) (O.D.)

It is clear that as shown in Table 5, all extracts were exhibited reduced power capacity, particularly all RBR extracts showed significantly high reducing power capacity when compared with that of RBL and BHT, whereas the FRAP of control sample of RBR extracted by ethanol $(2.812 \pm 0.0172)$ was significantly $(\mathrm{p}<0.05)$ higher than that extracted by methanol and acetone $(2.629 \pm 0.0156$ and 2.513 \pm 0.0040 , respectively) compared to BHT sample $(1.304 \pm 0.0059)$. The same trend of acting for FRAP was represented by RBL extracts which has a significant increasing $(\mathrm{p}<0.05)(2.520 \pm 0.0047)$ in the samples extracted by ethanol compared to that RBL sample extracted from methanol and acetone (2.393 \pm 0.0040 and $2.215 \pm 0.0043$, respectively) and BHT sample $(1.304 \pm 0.0059)$.
Irradiation process at dose levels of 3, 6, 9 and $12 \mathrm{kGy}$ enhanced FRAP for all extracts compared to non-irradiated and BHT samples for both RBR and RBL. It was found that all these extracts exhibited ferric reducing power greatly in dose level-dependent manner. In general, the reducing power capacity of all extracts may provide a significant indication of the potential antioxidant capacity of the plant parts. There was a difference among the different extract of Beta Vulgaris in reducing power compared to BHT as a positive control. Specifically, and briefly, the irradiation dose of $9 \mathrm{kGy}$ has a significant value of FRAP in all extracts (ethanol, methanol and acetone) obtained from RBR $(2.985 \pm 0.0035,2.771 \pm 0.0061$ and $2.655 \pm 0.0132$ respectively) and RBL (2.617 \pm $0.0052,2.503 \pm 0.0080$ and $2.358 \pm 0.0038$, respectively) as compared as corresponding control and other doses.

Table (5) : Ferric Reducing Antioxidant Power (FRAP) (O.D.) of non-irradiated and irradiated RBR and RBL extracts compared with BHT.

\begin{tabular}{|c|c|c|c|c|c|c|}
\hline \multirow{3}{*}{$\begin{array}{c}\gamma \text {-irradiation } \\
\text { doses }(k G y)\end{array}$} & \multicolumn{6}{|c|}{ Extraction Solvents } \\
\hline & \multicolumn{3}{|c|}{ RB Root } & \multicolumn{3}{|c|}{ RB Leaf } \\
\hline & Eth $80 \%$ & Meth $80 \%$ & Acet $80 \%$ & Eth $80 \%$ & Meth $80 \%$ & Acet $80 \%$ \\
\hline $\mathbf{0}$ & $\begin{aligned} & 2.812 \\
\pm & 0.0172^{\mathrm{Ba}}\end{aligned}$ & $\begin{aligned} & 2.629 \\
\pm & 0.0156^{\mathrm{Bb}}\end{aligned}$ & $\begin{aligned} & 2.513 \\
\pm & 0.0040^{\mathrm{Bc}}\end{aligned}$ & $\begin{aligned} & 2.520 \\
\pm & 0.0047^{\mathrm{Ca}}\end{aligned}$ & $\begin{aligned} & 2.393 \\
\pm & 0.0040^{\mathrm{Cb}}\end{aligned}$ & $\begin{aligned} & 2.215 \\
\pm & 0.0043^{\mathrm{Dc}}\end{aligned}$ \\
\hline 3 & $\begin{array}{c}2.823 \\
\pm 0.0342^{\mathrm{Ba}}\end{array}$ & $\begin{aligned} & 2.648 \\
\pm & 0.0081^{\mathrm{Bb}}\end{aligned}$ & $\begin{aligned} & 2.523 \\
\pm & 0.0057^{\mathrm{Bc}}\end{aligned}$ & $\begin{aligned} & 2.567 \\
\pm & 0.0071^{\mathrm{Ba}}\end{aligned}$ & $\begin{aligned} & 2.426 \\
\pm & 0.0088^{\mathrm{Bb}}\end{aligned}$ & $\begin{aligned} & 2.258 \\
\pm & 0.0039^{\mathrm{Cc}}\end{aligned}$ \\
\hline 6 & $\begin{aligned} & 2.847 \\
\pm & 0.0290^{\mathrm{Ba}}\end{aligned}$ & $\begin{aligned} & 2.655 \\
\pm & 0.0031^{\mathrm{Bb}}\end{aligned}$ & $\begin{aligned} & 2.533 \\
\pm & 0.0061^{\mathrm{Bc}}\end{aligned}$ & $\begin{aligned} & 2.588 \\
\pm & 0.0023^{\mathrm{Ba}}\end{aligned}$ & $\begin{aligned} & 2.448 \\
\pm & 0.0086^{\mathrm{Bb}}\end{aligned}$ & $\begin{array}{c}2.272 \\
\pm 0.0022^{\mathrm{BCc}}\end{array}$ \\
\hline 9 & $\begin{aligned} & 2.985 \\
\pm & 0.0035^{\mathrm{Aa}}\end{aligned}$ & $\begin{array}{c}2.771 \\
\pm 0.0061^{\mathrm{Ab}}\end{array}$ & $\begin{aligned} & 2.655 \\
\pm & 0.0132^{\mathrm{Ac}}\end{aligned}$ & $\begin{aligned} & 2.617 \\
\pm & 0.0052^{\text {Aa }}\end{aligned}$ & $\begin{aligned} & 2.503 \\
\pm & 0.0080^{\mathrm{Ab}}\end{aligned}$ & $\begin{aligned} & 2.358 \\
\pm & 0.0038^{\mathrm{Ac}}\end{aligned}$ \\
\hline 12 & $\begin{array}{c}2.828 \\
\pm 0.0232^{\mathrm{Ba}}\end{array}$ & $\begin{aligned} & 2.647 \\
\pm & 0.0154^{\mathrm{Bb}}\end{aligned}$ & $\begin{aligned} & 2.518 \\
\pm & 0.0030^{\mathrm{Bc}}\end{aligned}$ & $\begin{aligned} & 2.556 \\
\pm & 0.0033^{\mathrm{Ba}}\end{aligned}$ & $\begin{aligned} & 2.432 \\
\pm & 0.0025^{\mathrm{Bb}}\end{aligned}$ & $\begin{aligned} & 2.274 \\
\pm & 0.0067^{\mathrm{Bc}}\end{aligned}$ \\
\hline ВHT(200ppm) & $\begin{array}{c}1.304 \\
\pm 0.0059^{\text {Са }}\end{array}$ & $\begin{array}{c}1.304 \\
\pm 0.0059^{\mathrm{Ca}}\end{array}$ & $\begin{array}{c}1.304 \\
\pm 0.0059^{\mathrm{Ca}}\end{array}$ & $\begin{array}{c}1.304 \\
\pm 0.0059^{\mathrm{Da}}\end{array}$ & $\begin{array}{c}1.304 \\
\pm 0.0059^{\mathrm{Da}}\end{array}$ & $\begin{array}{c}1.304 \\
\pm 0.0059^{\mathrm{Ea}}\end{array}$ \\
\hline
\end{tabular}

Means with the same capital letter in the same columns are not significant $(p<0.05)$ different; means with the same small letter in the same rows are not significant $(p<0.05)$ different. 


\section{Antibacterial activity of non-irradiated and irradiated RBR and RBL extracts:}

As shown in Tables 6 and 7, all extracts exhibited considerable antibacterial activity against all tested microorganisms with slight differences between plant part, solvents, strains variety and gamma irradiation dose. Data indicated that there were observable significant differences between ethanol, methanol and acetone extracts of the non-irradiated RBR samples regarding growth inhibition of $S$. aureus, B. cereus, E. coli and $S$. typhimurium. The inhibition zones (mm) of $S$. aureus, B. cereus and E. coli bacteria reached its maximum value, $14.33 \pm 0.88$, $13.67 \pm 0.33$ and $12.33 \pm 0.33 \mathrm{~mm}$, respectively, for methanol extract, while it was $14.00 \pm 58 \mathrm{~mm}$ for S. typhimurium in the ethanol extract as shown in Table 6.

The majority trend in obtaining data summarized that the solvent extraction of both irradiated and non-irradiated RBR possesses higher antibacterial activity against selected bacteria than RBL, due to the presence of betanin and isobetanin.

The irradiation treatment randomly influenced the antibacterial activity of RBR extracts, where the inhibition zones of testing bacteria reached its maximal values at $9 \mathrm{kGy}$ which were $16.33 \pm 0.67$ and $15.17 \pm 44 \mathrm{~mm}$ of $S$. aureus, B. cereus for methanol and $17.00 \pm 0.58$ and $15.33 \pm 0.33 \mathrm{~mm}$ of $E$. coli and
S. typhimurium for ethanol, respectively.

Our data represented that the most of solvent extractions of red beet root, especially, ethanol and methanol extracts possess a moderate antibacterial activity, while acetone extract of RBR has no antibacterial activity against selected bacterial strains. On the contrary, red beet leave extracts mostly have no antibacterial activities.

On the other hand, in the case of RBL, it is obvious that there were slight differences between ethanol, methanol and acetone extracts of the nonirradiated RBL samples regarding growth inhibition of $S$. aureus, B. cereus, E. coli and S. typhimurium. The inhibition zones $(\mathrm{mm})$ of $S$. aureus and $S$. typhimurium, bacteria reached its maximum value was $13.33 \pm 0.67$ and $9.50 \pm 29 \mathrm{~mm}$ in ethanol extract, and $11.00 \pm 0.67$ and $9.60 \pm 0.40 \mathrm{~mm}$ of $B$. cereus and $E$. coli for methanol extract as shown in Table 6 . The irradiation process had the same manner of antibacterial activity of RBL extracts. Whereas, the inhibition zones of testing bacteria reached its maximum value which was $13.50 \pm 0.29 \mathrm{~mm}$ of $S$. aureus) at dose levels of $3 \mathrm{kGy}, 13.33 \pm 0.33 \mathrm{~mm}$, of B. cereus at dose level of $9 \mathrm{kGy}$ and $12.67 \pm 0.33$ of $S$. typhimurium at dose level of $9 \mathrm{kGy}$ for ethanol extracts and $11.00 \pm 0.58 \mathrm{~mm}$ of $E$. coli for methanol and acetone extracts as shown in Table 7. 
Table (6) : Antibacterial activity of non-irradiated and irradiated RBR extracts against some of food patho genic bacteria (zone of inhibition is expressed in $\mathrm{mm}$ ).

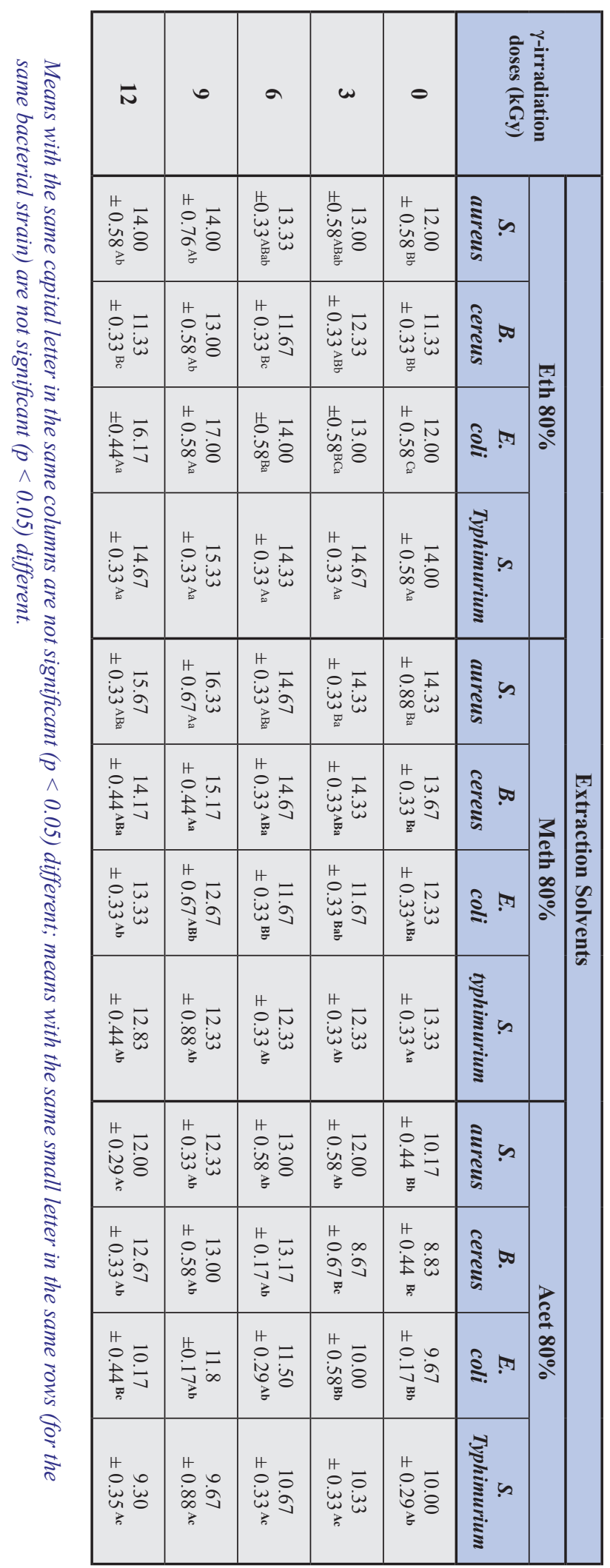


Table (7) : Antibacterial activity of non-irradiated and irradiated RBL extracts against some of food patho genic bacteria (zone of inhibition is expressed in $\mathrm{mm}$ ).

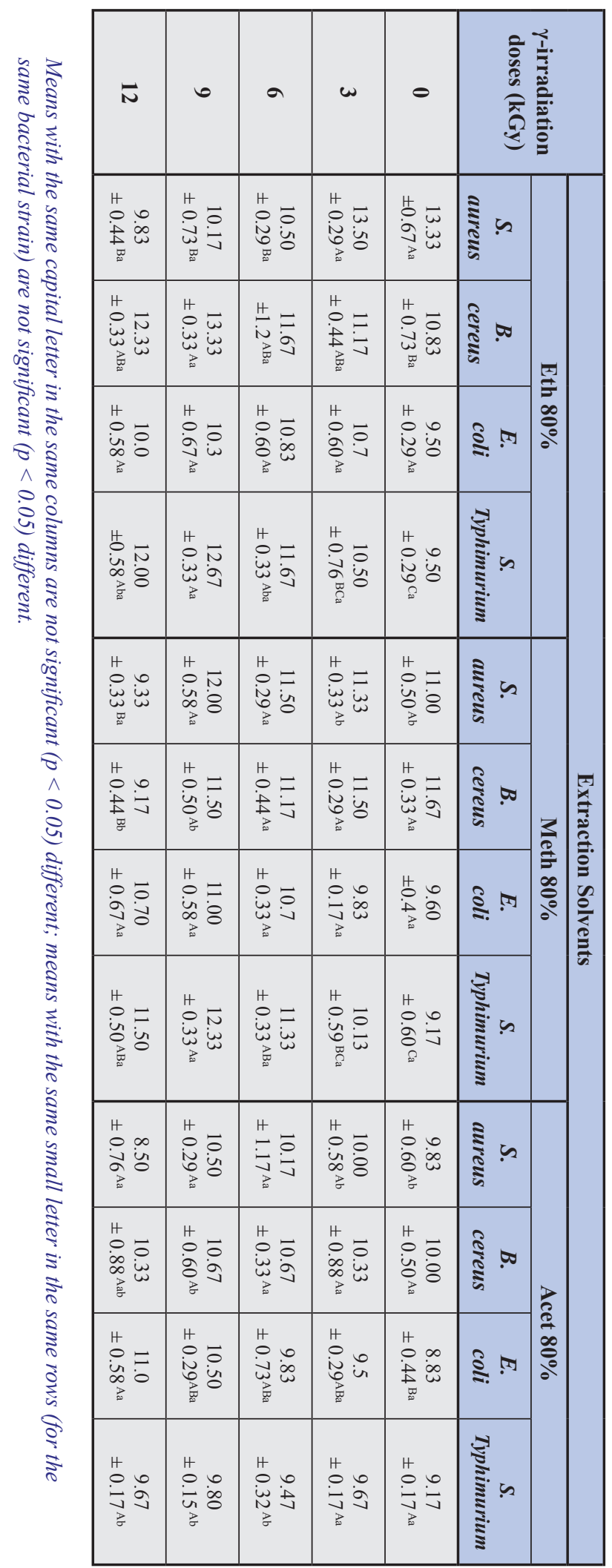




\section{DISCUSSION}

It is interesting to mention that, the phenolic and flavonoids contents depend on the cultivar, growing region, climate, maturity, cultivation practice, storage conditions and method used to obtain the juice (Poyrazoglu et al., 2002). These compounds are well known for their properties to scavenge free radicals and to inhibit lipid oxidation in vitro (Noda et al., 2002).

It would clarify that the higher extracting of phenolic compounds may be due to their higher polarity of the applied solvent (ethanol 80\%) and the good solubility for phenolic components from plant materials (Wieland et al., 2006).

The increase of phenolic content could be attributed to the higher extractability of these compounds in irradiated samples because of alterations in cellular compounds and release of bound or insoluble phenolics especially at high doses of irradiation (Behgar et al., 2011).

This significant increase in TPC and TFC could be attributed to the degradation of tannins present in RBR and RBL powder, having higher molecular weight into the release of simple phenolic compounds like Gallic acid, and Tannic acid. Irradiation may break this complex to facilitate a release of active ingredients, which were contributed to increasing the total phenolic content (Kumari et al., 2009). The enhanced antioxidant capacity/activity of a plant after irradiation is mainly attributed either to enzyme activity increase (e.g. Phenylalanine ammonia-lyase and peroxidase activity) or to the extractability increase from the tissues extractability by depolymerization and dissolution of cell wall polysaccharides by the irradiation (Alothman et al., 2009).

The current results exhibited that the highest antioxidant activity of RBR and RBL may be referred to their high content of phenolic compounds; this phenomenon is in a good agreement with Heim et al. (2002) The extract is capable of scavenging free radicals, thus preventing the initiation and propaga- tion of free-radical-mediated chain reactions. This can be beneficial in the preservation of foodstuffs, drug products and cosmetics, where free radical-mediated chain reactions result in lipid oxidation and subsequent deterioration of the products (Dastmalchi et al., 2008).

The antioxidant activity is due to the presence of polyphenols or Gallic acid. As mentioned earlier, this increase in total phenolics and flavonoids was thus suggestive of their enhanced antioxidant properties. Kumari et al. (2009) also showed similar results with Triphala, wherein they have found out an increase in Gallic acid concentration and total phenolics in the water extract due to irradiation that leads to increase in the antioxidant property.

Radiation treatments have been shown to either increase or decrease the antioxidant content of fresh plant products, which is dependent on the dose delivered, exposure time and the raw material used. The enhanced antioxidant capacity/activity (correlation with the total phenolic content accordingly antibacterial activity) of a plant after irradiation is mainly attributed either to increase enzyme activity (e.g., phenylalanine ammonia-lyase and peroxidase activity) or to the increased extractability from the tissues (Bhatt et al., 2007). Also, as mentioned earlier, the increase or decrease in antioxidants (correlation with the total phenolic content) of irradiated samples might also be dependent on the solvents used for extraction (Khattak et al., 2008).

However, depending on the technological criteria and the specific type of produce, the mechanism of increase or decrease in antioxidant compounds might vary. For instance, quantitative differences in the constituents of nutmeg oil, as well as an increased amount of phenolic acids, were detected after $\gamma$-irradiation, which was attributed to the degradation of tannins and consequently higher extractability of phenolic acids (Variyar et al., 1998).

The decrease in antioxidants caused in acetone 
$80 \%$ extracts of the irradiated RBL at 3, 6, 9 and 12 kGy compared BHT could be attributed in general, to the formation of radiation-induced degradation products or the formation of free radicals (Sajilata and Singhal, 2006). Breitfellner et al. (2002) reported that $\gamma$-irradiation (1-10 kGy) of strawberries lead to the degradation of phenolic acids like cinnamic, p-coumaric, gallic, and hydroxybenzoic acids. The hydroxylation (decomposition) of these phenolic acids has been attributed to the formation of free hydroxyl (OH-) radicals during the treatment.

The results indicated that there was a correlation between the ferric reducing antioxidant power and phenolic contents of the extracts. This emphasizes the importance of phenolic contents in reducing power observed in this study, and this may be due to their potent electron donating abilities (Bilot et al., 2012).

Red beet root has antibacterial activity towards Gram-positive and Gram-negative bacteria. Inhibition zone, which had strong activity was $\geq 20 \mathrm{~mm}$ while, the moderate activity was in inhibition zone $<20$ to $12 \mathrm{~mm}$ and no inhibition zone was $\leq 12 \mathrm{~mm}$ (Ait-Ouazzou et al., 2011). However, Gram-positive bacteria, e.g., S. aureus and B. cereus represented less resistance compared to Gram-negative bacteria, e.g., E. coli and S. typhimurium in the present study. Beet root had a higher content of phenols (Baydar et al., 2004 and Canadanovic-Brunet et al., 2011). These concluded data are in the same trend with John et al. (2017) who found that betanin and isobetanin had antimicrobial activity.

In addition, some other components like flavonoids, tannins and saponins. Whereas, phenolic compounds possess high levels of antimicrobial activity. Phenolic compounds affect mainly the cellular membranes, altering their function and in some instances their structure, causing swelling and increasing their permeability. The increases in cytoplasmic membrane permeability appear to be a consequence of the loss of the cellular $\mathrm{pH}$ gradient, decreased ATP levels, and the loss of the proton motive force, which lead to cell death.

The inhibition of microorganisms by phenolic compounds may be due to iron deprivation or hydrogen bonding with vital proteins such as microbial enzymes (Scalbert, 1991). Phenolic compounds notably proanthocyanidins (often called condensed tannins) are vulnerable to polymerization in air through oxidizing reactions. Therefore, an important factor governing their toxicity is their polymerization size. Oxidized condensation of phenols may result in the toxification of microorganisms.

On the other hand, polymerization can result in the detoxification of phenols (Field and Lettinga, 1992). These support the fact polyphenols may be responsible for the antimicrobial activities of the extracts of the screened plants.

Another study conducted on ciprofloxacin (AlMohizea et al., 2007) showed that antimicrobial activity was not affected by gamma-irradiation treatment up to $100 \mathrm{kGy}$. The difference in antibacterial activity may suggest some chemical changes in the structure of active compounds upon irradiation at comparatively higher doses, i.e. $25 \mathrm{kGy}$.

Generally, this study indicates that extracts obtained from red beet leaves and roots possess considerable amounts of phenolic, flavonoid contents, antioxidant, antibacterial activities and significant radical scavenging activity towards both DPPH and FRAP assay. Results exhibited a positive relationship between the antiradical activities of beet leaves and roots and the contents of total phenolics and flavonoids. Moreover, gamma irradiation doses up to 9 kGy can improve the antioxidant activity of red beet leave and root ethanol extracts which might be a potent source of antioxidants, and has potential as a value-added ingredient for functional foods. In future studies, it would be desirable to employ such experimental conditions that can more specifically reflect the in vivo antioxidant activities of the ob- 
tained extracts.

\section{REFERENCES}

- Ait-Ouazzou, A.; Lorán, S.; Bakkali, M.; Laglaoui, A.; Rota, C.; Herrera, A. and Pagána, R. (2011): Chemical composition and antimicrobial activity of essential oils of Thymus algeriensis, Eucalyptus globulus and Rosmarinus officinalis from Morocco. J. Sci. Food Agri., 91: 2643.

- Al-Mohizea, A.M.; El-Bagory, I.M.; Alsarra, I.A.; Al-Jenoobi, F.I. and Bayomi, M.A. (2007): Effect of gamma radiation on the physicochemical properties of ciprofloxacin in solid state. J. Drug Del. Sci. Tech., 17: 211.

- $\quad$ Alothman, M.; Bhat, R. and Karim, A.A. (2009): Effects of radiation processing on phytochemicals and antioxidants in plant produce. Trends Food Sci. Tech., 20: 201.

- Andrews, J.M. (2001): Determination of minimum inhibitory concentration. J. Antimicrob. Chemother., 48: S1, 5 .

- Arabshahi-Delouee, S. and Urooj, A. (2007): Antioxidant properties of various solvent extracts of mulberry (Mocus indica L.) leaves. Food Chem., 102: 1233.

- Baydar, H.; Sağdiç, O.; Gülcan, Ö. and Karadoğan, T. (2004): Antimicrobial activity and composition of essential oils from Origanum, Thymbra and Satureja species with commercial importance in Turkey. Food Cont., 15: 169.

- Behgar, M.; Ghasemi, S.; Naserian, A.; Borzoie, A. and Fatollahi, H. (2011): Gamma radiation effects on phenolics, antioxidants activity and in vitro digestion of pistachio (Pistachia vera) hull. Rad. Phys. Chem., 80: 963.

- Bennett, J.V.; Brodie, J. L.; Benner, E.J. and Kirb, W.M.M. (1966): Simplified, accurate method for antibiotic assay of clinical specimens. Applied Microbiol., 14: 170 .
- $\quad$ Bhatt, R.; Sridhar, K.R. and Tomita-Yokotani, K. (2007): Effect of ionizing radiation on antinutritional features of velvet bean seeds (mucuna pruriens). Food Chem., 103: 860.

- $\quad$ Bilto, Y.Y.; Suboh, S.; Aburjai, T. and Abdalla, S. (2012): Structure-activity relationships regarding the antioxidant effects of the flavonoids on human erythrocytes. Nat. Sci., 9: 740 .

- Breitfellner, F.; Solar, S. and Sontag, G. (2002): Effect of $\gamma$-irradiation on phenolic acids in strawberries. J. Food Sci., 67: 517.

- Canadanovic-Brunet, J.M.; Savatovic, S.S.; Cetkovic, G.S.; Vulić, J.J.; Dj ilas, S.M.; Markov, S.L. and Cvetković, D.D. (2011): Antioxidant and antimicrobial activities of beet root pomace extracts. Czech J Food Sci., 29: 575.

- Dastmalchi, K.; Dorman, H.J.D; Oinonen, P.P; Darwis, Y.; Laakso, I. and Hiltunen, R. (2008): Chemical composition and in vitro antioxidative activity of a lemon balm (Melissa officinalis L.) extract. LWT-Food Sci. Tech., 41: 391.

- Fernández-Ginés, J.M.; Fernández-López, J.; Sayas-Barberá, E. and Pérez-Alvarez, J.A. (2005): Meat products as functional foods: a review. J. Food Sci., 70: R37.

- Fernández-López, J.; Viuda-Martos, M.; Sendra, E.; Sayas-Barberá, E.; Navarro, C. and PérezAlvarez, J.A. (2007): Orange fibre as potential functional ingredient for dry-fermented sausages. Eur. Food Res. Tech.,226: 1.

- Field, J.A. and Lettinga, G. (1992): Toxicity of tannic compounds to microorganisms. Plants Polyphenols: Synthesis, Properties, Significance. Basic Life Sci., 59: 673.

- Gülçin, I.; Bursal E.; Şehitoğlu, H.M.; Bilsel, M. and Gören, A.C. (2010): Polyphenol contents and antioxidant activity of lyophilized aqueous extract of propolis from Erzurum, Turkey. Food Chem. Toxic., 48: 2227. 
- Hanato, T.; Kagawa, H.; Yasuhara, T. and Okuda, T. (1988): Two new flavonoids and other constituents in licorice root: their relative astringency and radical scavenging effects. Chem. Pharm. Bull., 36: 2090.

- Heim, K.E.; Tagliaferro, A.R. and Bobilya, D.J. (2002): Flavonoid antioxidants chemistry, metabolism and structure-activity relationship. J. of Nutr. Biochem., 13: 572.

- John, S.; Monica, S.J.; Priyadarshini, S.; Sivaraj, C. and Arumugam, P. (2017): Antioxidant and Antibacterial Activities of Beta vulgaris L. Peel Extracts. Int. J. of Pharma. Res. Health Sci., 5: 1974.

- Kähkönen, M.P.; Hopia, A.I.; Vuorela, H.J.; Rauha, J.P.; Pihlaja K.; Kujala, T.S. and Heinonen, M. (1999): Antioxidant activity of plant extracts containing phenolic compounds. J. Agri. Food Chem., 47: 3954.

- Kaur, C. and Kapoor, H.C. (2001): Antioxidants in fruits and vegetables - the millennium's health. Int. J. Food Sci. Tech., 36: 703.

- Khattak, K.F.; Simpson, T.J. and Ihasnullah, (2008): Effect of gamma irradiation on the extraction yield, total phenolic content and free radical-scavenging activity of Nigella staiva seed. Food Chem., 110: 967.

- Kujala, T.; Loponen, J. and Pihlaja, K. (2001). Betalains and phenolics in red beetroot (Beta vulgaris) peel extracts extraction and characterization. Z. Naturforsch C., 56: 343 .

- $\quad$ Kumari, N.; Kumar, P.; Mitra, D.; Prasad, B.; Tiwary, B.N. and Varshney, L. (2009): Effects of ionizing radiation on microbial decontamination, phenolic contents, and antioxidant properties of triphala. $J$. Food Sci., 74: M109.

- Loaharanu, P. and Thomas, P. (Eds.), (2001). Irradiation for Food Safety and Quality. Proceeding of the FAO/IAEA/WHO International conference on Ensuring the Safety and Quality of Food through Radiation Processing, October 19-22, 1999, Antalya, Turkey. Technomic Publishing co. Inc., Lancaster, PA.
- Makris, D.P.; Boskou G. and Andrikopoulos, N.K. (2007): Polyphenolic content and in vitro antioxidant characteristics of wine industry and other agri-food solid waste extracts. J. Food Composition and Analysis, 20:125.

- Morehouse, K.M. (2002): Food irradiation-US regulatory considerations. Rad. Phys. Chem., 63: 281.

- $\quad$ Noda, Y.; Kaneyuka, T.; Mori, A. and Packer, L. (2002): Antioxidant activities of pomegranate fruit extract and its anthocyanidins: delphinidin, cyanidin, and pelargonidin. J. Agric. Food Chem., 50: 166.

- Ordon, J.D.; Gomez, M.A. and Vattuone, M.I. (2006): Antioxidant activities of Sechium edule (Jacq.) Swartz extracts. Food Chem., 97:452.

- Oyaizu, M. (1986): Studies on product of browning reaction prepared from glucose amine. Japanese J. Nut., 44: 307.

- Pedreno, M.A. and Escribano, J. (2001): Correlation between antiradical activity and stability of betanine from Beta vulgaris $\mathrm{L}$ roots under different $\mathrm{pH}$, temperature and light conditions. J. Sci. Food Agri., 81: 627.

- Poyrazoglu, E.; Gkmen, V. and Artık, N. (2002): Organic acids and phenolic compounds in pomegranates (Punica granatum L.) grown in Turkey. J. Food Composition and Analysis, 15: 567.

- $\quad$ Riboli, E. and Norat, T. (2003): Epidemiologic evidence of the protective effect of fruit and vegetables on cancer risk. Am. J. Clin. Nutr., 78: 559.

- Sajilata, M.G. and Singhal, R.S. (2006): Effect of irradiation and storage on the antioxidative activity of cashew nuts. Rad. Phys. Chem., 75: 297.

- SAS (2004): Statistical Analysis System, SAS User, s Guide Release. 6.04 Ed. Statistics SAS Institute Inc. Editors, CARY, NC.

- Scalbert, A. (1991): Antimicrobial properties of tannins. Phytochemistry, 30: 3875. 
- Vaithiyanathan, S.; Naveena, B.M.; Muthukumar, M.; Girish, P.S. and Kondaiah, N. (2011): Effect of dipping in pomegranate (Punica granatum) fruit juice phenolic solution on the shelf life of chicken meat under refrigerated storage $\left(4^{\circ} \mathrm{C}\right)$. Meat Sci., 88: 409.

- Variyar, P.S.; Bandyopadhyay, C. and Thomas, P. (1998): Effect of $\gamma$-irradiation on the phenolic acid of some Indian spices. Int. J. Food Sci. Tech., 33: 533.

- Wieland, P.; Ferran, S.; Wilfried, D.; Andreas, P.; Irene G. and Diego, J. (2006): An industrial approach in the search of natural antioxidants from vegetable and fruit wastes. Food Chem., 97: 137.

- Zobel, A.M. (1997): Coumarins in fruit and vegetables. In F.A. Tomas-Barberan, and R. J. Robbins (Eds.), Photochemistry of Fruit and Vegetables. Oxford, UK; Clarendon Press: 173. 